\title{
The Carbon Metabolism and Swelling of Fusarium culmorum Conidia
}

\author{
By R. MARCHANT AND MONICA F. WHITE \\ Department of Botany, University College, Gower Street, London, W.C.1
}

(Accepted for publication 13 February 1967)

\begin{abstract}
SUMMARY
The substrate of basal respiration of conidia of Fusarium culmorum (W. G. Smith) Sacc. was found to be a mixture of triglycerides. The rate of utilization of this substrate increased when the conidia germinated. One of the main products of glucose metabolism in the germinating conidium was glucosamine which was a major constituent of the hyphal and conidial walls. The conidia fixed atmospheric carbon dioxide primarily into one compound, probably glutamine. Experiments on the conditions necessary for the swelling of the conidia indicated that metabolic pathways are involved, possibly terminating in the formation of glucosamine as the compound which initiates swelling. The use of tritiated water eliminated a theory of selective permeability as the mechanism for swelling; a theory based on a change in the elasticity of the conidial wall is now proposed.
\end{abstract}

\section{INTRODUCTION}

The macroconidia of Fusarium culmorum have been shown to require carbon and nitrogen sources for germination (Marchant \& White, 1966) and under these conditions the conidia swell because of the uptake of water. The conidia are, however, capable of existing for quite long periods on their reserve carbon source, which they respire slowly. Since both germination and swelling require an external carbon source it was necessary to gain some knowledge of the carbon metabolism of the conidia. Studies on the carbon metabolism of fungi have confirmed that the basal metabolic pathways found in other organisms are operative in fungi (Moses, 1957; Gottlieb, 1963). It is obvious, however, that different fungi differ in detail and it is not possible to generalize about the carbon metabolism in specific organisms.

The germination of conidia of Fusarium solani f. phaseoli and certain aspects of their carbon metabolism were studied by Cochrane, Cochrane, Simon \& Spaeth (1963), Cochrane, Cochrane, Collins \& Serafin (1963), Cochrane, Berry, Simon, Cochrane, Collins, Levy \& Holmes (1963) and Cochrane, Cochrane, Vogel \& Coles (1963). It has been pointed out, however, that the germination of the conidia of $F$. culmorum differs in more than one respect from that of $F$. solani (Marchant \& White, 1966). Lopez \& Fergus (1966) examined the nutritional requirements of $F$. roseum and their results are in general agreement with the utilization of sugars already shown (Marchant \& White, 1966) for the conidia of F. culmorum.

In the present work the products of glucose metabolism in conidia of Fusarium culmorum were studied by supplying $\left[\mathrm{U}-{ }^{14} \mathrm{C}\right] \mathrm{glucose}$, and examining the identity and distribution of the products. The substrate of basal respiration, which was identified 
as a fat, was extracted and identified by thin-layer chromatography and gas chromatography. It was found that conidia were capable of fixing atmospheric carbon dioxide; therefore the effect of carbon dioxide concentration on the rate and products of fixation were examined.

That the spores of many fungi swell before germination has been noted many times. This swelling has been ascribed to the uptake of water, in many cases to a passive process in the absence of any nutrients. There are, however, many fungi which produce spores that are only capable of swelling in the presence of nutrients. Ekundayo \& Carlile (1964) examined the swelling of sporangiospores of Rhizopus arrhizus, and showed that these required a utilizable carbon source in order to swell at all, and a nitrogen source and various ions to reach maximal swelling. A mechanism for the active swelling of $R$. arrhizus spores was postulated by Ekundayo (1966) which involves the enzyme, protein disulphide reductase (EC 1.8.4.1, Nickerson \& Falcone, 1959; Hatch \& Turner, 1960).

Marchant \& White (1966) reported on the swelling of conidia of Fusarium culmorum which was associated with germination. The swelling of these conidia comprised two components, the expansion of the mucilaginous sheath (Marchant, 1966a; Marchant, $1966 \mathrm{~b}$ ) and the swelling of the conidium itself because of water uptake. The swelling of the conidium was shown to take place only in the presence of carbon and nitrogen sources. In the present work a more complete study of this process has been made.

\section{METHODS}

Organism. The strain of Fusarium culmorum used was obtained from the Commonwealth Mycological Institute (IMI 96283). The organism was grown and the conidia harvested as described previously (Marchant \& White, 1966).

Extraction and characterization of storage lipid. The lipid was extracted from ungerminated and germinated conidia by the following method. The conidia (initial dry wt. $40 \mathrm{mg}$.) were centrifuged down from the suspending medium and killed by immersion in boiling water for $3 \mathrm{~min}$. The conidia were then extracted with $2 \mathrm{ml}$. $95 \%(\mathrm{v} / \mathrm{v})$ methanol in water at $70^{\circ}$ for $15 \mathrm{~min}$. The methanol extraction was then repeated twice and the residue further extracted twice with $2 \mathrm{ml}$. diethyl ether at $35^{\circ}$ for $15 \mathrm{~min}$. The combined methanol extracts were partitioned against ether and water, and all the ether extracts then combined. Where dry weights were required the extract was dried to a constant weight at $50^{\circ}$ and compared with the total dry wt. of a parallel sample of conidia. Dry weight and lipid determinations were made at least in duplicate. Some lipid determinations were done by Soxhlet extraction with ether and methanol.

The composition of the extracted lipid was determined by running thin-layer chromatograms. The glass plates used were $10 \times 20 \mathrm{~cm}$. and coated with a $250 \mu$ thick layer of silica gel, activated at $80^{\circ}$ for $20 \mathrm{~min}$. The sample was applied to the plates in $0 \cdot 1 \mathrm{ml}$. ether $(60-80 \mu \mathrm{g} . / \mathrm{spot})$ and then developed for $10 \mathrm{~cm}$. in a solvent of light petroleum (b.p. $\left.40-60^{\circ}\right)+$ ether + glacial acetic acid $(90+10+1$, by vol.). The chromogenic reagents used were $5 \%$ phosphomolybdic acid in ethanol and heating to $80^{\circ}$, and the bromothymol blue reagent (Randerath, 1963). A standard of tripalmitin containing small quantities of the mono- and di-glycerides was used.

To identify the components of the major triglyceride spot the entire lipid extract from $40 \mathrm{mg}$. dry-wt. conidia was spread across the width of a plate. The triglyceride 
band was identified by spraying one edge of the plate and the remainder of the band then scraped off and eluted. The triglyceride was deacylated by the method of Morgan, Hanahan \& Ekholm (1963), with $0.5 \mathrm{~N}-\mathrm{NaOH}$ in methanol. The products were partitioned between chloroform and water; the chloroform fraction, containing the methyl esters of fatty acids, was retained for gas chromatography. The water fraction was separated on a thin-layer plate by using $n$-butanol +acetic acid +water $(5+1+2$, by vol.) as solvent and ammoniacal silver nitrate as the chromogenic reagent. A standard was run to identify the glycerol component.

The methyl esters of the fatty acids were dried and taken up in light petroleum. A sample $(0.5 \mu 1$.) was then run on a Pye panchromatogram through a polyethylene glycol adipate column (PEGA) and an Apiezon L column (APL). The percentage of each acid was calculated from the run on the PEGA column.

Utilization of storage lipid. The utilization of lipid through the glyoxylate pathway was investigated by assaying the isocitrate lyase activity in ungerminated and germinated conidia. The assay was done as described by Kornberg \& Madsen (1958). The conidia were left intact for the assay but were frozen and then thawed to increase their permeability; the freezing procedure increased the observed activity by $50 \%$.

The effect of external carbon sources, glucose and glucose + ammonium sulphate on the oxidation of the lipid reserve material was investigated by using uniformly labelled $\left[{ }^{14} \mathrm{C}\right]$ glucose. The experiment was done in Warburg flasks at $25^{\circ}$; conidia were either supplied with $150 \mu$ moles [U-14 C]glucose or $150 \mu$ moles [U- ${ }^{14}$ C]glucose + $30 \mu$ moles ammonium sulphate, in $3 \mathrm{ml} .0 .03 \mathrm{M}$-phosphate buffer (pH 6.5). Total oxygen uptake was measured and samples of the total ${ }^{14} \mathrm{CO}_{2}$ absorbed by the $0.2 \mathrm{ml}$. $10 \%(\mathrm{w} / \mathrm{v}) \mathrm{KOH}$ in the centre well were counted in a liquid scintillation counter with toluene scintillator liquid. After subtraction of oxygen uptake due to basal respiration the amount of oxygen taken up was compared with the theoretical amount calculated from the ${ }^{14} \mathrm{CO}_{2}$ evolved.

The fate of $\left[{ }^{14} \mathrm{C}\right]$ glucose in germinating conidia. The experiment was done in Warburg flasks and the conidia were supplied with $100 \mu$ moles [U- $\left.{ }^{14} \mathrm{C}\right]$ glucose $(2 \mu \mathrm{C})$. One experiment was done in which the conidia were supplied with $100 \mu$ moles ammonium sulphate and a duplicate without ammonium sulphate. The experiment was done in $3 \mathrm{ml} .0 .03 \mathrm{M}$-phosphate buffer $\left(\mathrm{pH} \mathrm{6.5)}\right.$ for $1.5 \mathrm{hr}$ at $25^{\circ}$. At the end of the experiment the centre well contents $(0.2 \mathrm{ml} .10 \%, \mathrm{w} / \mathrm{v}, \mathrm{KOH})$ were washed out and made up to $5 \mathrm{ml}$. to give an estimate of ${ }^{14} \mathrm{CO}_{2}$ evolved from respiration. The conidia themselves were centrifuged down from the medium, washed once with ice-cold water, and the supernatant fluid + washings made up to $5 \mathrm{ml}$. The conidia were extracted twice with hot water $\left(80^{\circ}\right)$ and these extracts made up to $5 \mathrm{ml}$. The conidia were then extracted twice with ethanol at $50^{\circ}$ and these extracts also made up to $5 \mathrm{ml}$. The residue was suspended in $5 \mathrm{ml}$. water. Portions $(0.4 \mathrm{ml}$.) of the samples were counted in a liquid scintillation counter with toluene scintillator liquid. A sample of the initial glucose was also counted. Quenching errors were checked by adding $0.02 \mathrm{ml}$. $(0.008 \mu \mathrm{c})$ of the standard glucose to the samples and noting the increase in count. It was found that quenching effects were negligible.

The remainder of the water extract was evaporated to dryness and then taken up in $0.25 \mathrm{ml} .50 \%(\mathrm{v} / \mathrm{v})$ ethanol in water. The entire extract was spotted on $3 \mathrm{MM}$ Whatman paper and developed in $75 \%(\mathrm{w} / \mathrm{w})$ phenol in water, then with butanol+ 
acetic acid + water $(90+29+10$, by vol.). The final chromatograms were put over $\mathrm{X}$-ray film for 4 weeks before being sprayed with ninhydrin.

The remainders of the conidial residues were similarly collected and hydrolysed with $1 \mathrm{ml}$. $\mathrm{N}_{-}-\mathrm{H}_{2} \mathrm{SO}_{4}$ for $3 \mathrm{hr}$ at $100^{\circ}$. Two drops of bromothymol blue were then added to the hydrolysis mixture, followed by saturated barium hydroxide solution until the mixture was alkaline. Carbon dioxide was bubbled through to re-acidify the solution and then one drop of ammonium hydroxide (sp.gr. 0.88) was added. The precipitate was centrifuged down, washed and the supernatant fluid and washings combined. About $83 \%$ of the total radioactivity from the residue was recovered by this method. The entire hydrolysis samples were spotted on $3 \mathrm{MM}$ Whatman paper and developed for $40 \mathrm{hr}$ in ethyl acetate + acetic acid + water $(3+3+1$, by vol.). One each of the duplicate samples had $150 \mu \mathrm{g}$. [U-14 C]glucose added to it as a marker, and in addition a marker containing $150 \mu \mathrm{g}$. each of glucose, fructose, galactose, arabinose and xylose was run. The chromatograms were put over X-ray film for 4 weeks before being sprayed with ammoniacal silver nitrate.

Carbon-dioxide fixation. Conidia were germinated in a medium containing the following: $3000 \mu$ moles glucose, $1500 \mu$ moles ammonium sulphate in $25 \mathrm{ml} .0 .03 \mathrm{M}$ phosphate buffer ( $\mathrm{pH}$ 6.5). The conidia were contained in a closed system of capacity $1100 \mathrm{ml}$. The whole system was flushed through with air from which the $\mathrm{CO}_{2}$ had been removed with Carbosorb. The concentration of $\mathrm{CO}_{2}$ was then returned to $0.04 \%$ (v/v) by introducing $1 \mathrm{ml} .2 \mathrm{~N}_{2}-\mathrm{H}_{2} \mathrm{SO}_{4}$ on to a calculated quantity of $0 \cdot 1 \mathrm{M}-\mathrm{KH}{ }^{14} \mathrm{CO}_{3}$. The system was shaken at $25^{\circ}$ for $42 \mathrm{hr}$. Half-way through the experiment the system was flushed out and the ${ }^{14} \mathrm{CO}_{2}$ replenished. At the end of the experiment the germinated conidia were centrifuged down and resuspended in $5 \mathrm{ml}$. water; a sample was counted to give the total incorporation of ${ }^{14} \mathrm{CO}_{2}$. The remainder of the material was then extracted with hot water and ethanol, as described previously, to give the distribution of incorporated ${ }^{14} \mathrm{C}$ in the fractions of conidia.

The effect of $\mathrm{CO}_{2}$ concentration on fixation by germinating conidia was examined as follows. Katz flasks ( $50 \mathrm{ml}$.) were used containing $1500 \mu$ moles glucose, $750 \mu$ moles ammonium sulphate in $12.5 \mathrm{ml} 0.03 \mathrm{M}$-phosphate buffer (pH 6.5). In the centre well of each flask was placed a volume of $\mathrm{Na}_{2}{ }^{14} \mathrm{CO}_{3}$ calculated to yield the following concentrations $(\%, v / v)$ of ${ }^{14} \mathrm{CO}_{2} ; 0.035,0.07,0.10,0.50$ and 0.83 . The flasks were gassed with $\mathrm{CO}_{2}$-free air and then $1 \mathrm{ml} .2 \mathrm{~N}-\mathrm{H}_{2} \mathrm{SO}_{4}$ was injected into each flask through a vaccine stopper. The flasks were shaken for $22 \mathrm{hr}$ at $25^{\circ}$ before the conidia were killed by adding $1 \mathrm{ml} .20 \%$ (w/v) trichloroacetic acid. After being centrifuged down and resuspended samples of the conidia were counted in the scintillation counter. A dry weight determination on a sample of the conidia and a count of the original $\mathrm{Na}_{2}$ ${ }^{14} \mathrm{CO}_{3}$ allowed the $\mathrm{CO}_{2}$-fixation to be expressed as $\mu \mathrm{g} .{ }^{14} \mathrm{CO}_{2}$ fixed/g. dry-wt conidia $/ \mathrm{hr}$.

The material left from the $0.035 \%$ and $0.83 \%{ }^{14} \mathrm{CO}_{2}$ flasks was extracted with $80 \%$ (v/v) ethanol in water and partitioned against light petroleum. The water extract was chromatographed in phenol, then butanol + acetic acid + water, as described previously, and the chromatogram put over X-ray film. The ether extract was run on a thin-layer chromatogram before also being put over X-ray film.

Conidial swelling. Conidial swelling was measured by using a micrometer eyepiece; a random sample of 100 conidia was counted in each case. From these measurements the mean maximum spore widths and the standard errors were calculated. The basal medium used for experiments consisted of: $500 \mu$ moles glucose, $100 \mu$ moles am- 
monium sulphate in $10 \mathrm{ml} .0 .03 \mathrm{M}$-phosphate buffer ( $\mathrm{pH} \mathrm{6.5)}$. The nutrients were always used at these concentrations unless otherwise stated. Nitrate was supplied as

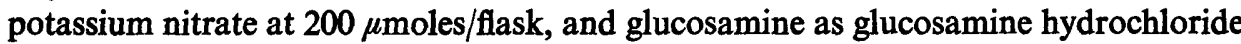
at $500 \mu \mathrm{moles} /$ flask. Sodium acetate was used in equivalent amounts to gluccse $\left(1000 \mu\right.$ moles/flask). The experiments were made in $50 \mathrm{ml}$. conical flasks at $25^{\circ}$ on a reciprocal shaker.

Carbon dioxide concentrations, A concentration of $5 \%(\mathrm{v} / \mathrm{v}) \mathrm{CO}_{2}$ in air was achieved by using gas, washed in water, from a cylinder containing $95 \%(\mathrm{v} / \mathrm{v})$ air $+5 \%(\mathrm{v} / \mathrm{v})$ $\mathrm{CO}_{2}$. Conidia were maintained in a $\mathrm{CO}_{2}$-free atmosphere by continually passing $\mathrm{CO}_{2}$ free air through the flask.

Manometric methods. Oxygen uptake was measured in the usual Warburg apparatus at $25^{\circ}$, with direct absorption of $\mathrm{CO}_{2}$ by $10 \%(\mathrm{w} / \mathrm{v}) \mathrm{KOH}$ in the centre well. The conidia were supplied with $150 \mu$ moles glucose $+30 \mu$ moles ammonium sulphate or 150 $\mu$ moles glucosamine hydrochloride in $3 \mathrm{ml} .0 .03 \mathrm{M}$-phosphate buffer (pH 6.5).

Permeability of conidia to tritiated water. Conidia were shaken in $20 \mathrm{ml}$. nutrient solution, containing either glucose + ammonium sulphate or glucose, for $4 \mathrm{hr}$ at $25^{\circ}$. Four duplicate sets of $2 \mathrm{ml}$. samples were removed from each flask. One pair of duplicates from each flask was centrifuged, the deposit washed once with $2 \mathrm{ml}$. nontritiated water and then resuspended in $2 \mathrm{ml}$. water. The centrifuged deposits of other sets of duplicates were similarly washed 2,4 or 8 times. Portions $(0.05 \mathrm{ml}$.) of these samples were then counted for radioactivity by using toluene scintillator liquid in a liquid scintillation counter.

\section{RESULTS}

\section{Characterization and utilization of storage lipid}

Thin-layer chromatography of the entire lipid extracts revealed three major spots only. The largest and rather elongated spot, with an $R_{F}$ value of $0.4-0.55$, corresponded to the triglyceride fraction of the tripalmitin standard. Two smaller spots with $\boldsymbol{R}_{\boldsymbol{f}}$ values of 0.17 and 0.07 corresponded with the di- and mono-glyceride fractions of the standard. There were also faint spots close to the solvent front, probably representing long-chain hydrocarbon compounds (Malins \& Mangold, 1960). Material left at the origin gave a positive yellow coloration with an ammonium vanadate + ammonium molybdate spray, indicating the presence of phospholipid. The elongated nature of the large triglyceride spot, irrespective of the loading of the plate, suggested that it represented a mixture of triglycerides.

The water fraction of the deacylated triglyceride yielded only glycerol, as would be expected if the extract contained only glycerides. The gas chromatography of the methyl esters of the fatty acids of the triglyceride fraction gave the results shown in Table 1, in which the percentage composition has been calculated and the probable identity of the acids given. These acids combined into triglyceride would give the large number of glycerides necessary to produce the characteristically shaped spot on the chromatograms.

The concentration of lipid in the conidia was examined before and after germination and also after shaking in the presence of a carbon source only. Conidia were shaken for $22 \mathrm{hr}$ at $25^{\circ}$ in media containing $1000 \mu$ moles glucose $\pm 150 \mu$ moles ammonium sulphate in $25 \mathrm{ml} .0 .03 \mathrm{M}$-phosphate buffer ( $\mathrm{pH} \mathrm{6.5)}$. The concentrations of lipid and percentages of the total dry weight are given in Table 2. 
In the conidia shaken in glucose alone there was either no utilization of lipid or the net synthesis had not kept pace with the increase in dry weight, resulting in a decrease in the percentage of lipid. Glucose + ammonium sulphate treatment, however, resulted in a net increase of lipid; but once again a decrease in the percentage lipid of the total dry weight.

To see whether the utilization of lipid was affected by treatment with glucose + ammonium sulphate the isocitrate lyase activity in germinated and ungerminated conidia was examined. The conidia were germinated as for the lipid determinations for $20 \mathrm{hr}$. The mean isocitrate lyase activity for ungerminated conidia, obtained from duplicated experiments, was $3.5 \mu \mathrm{g}$. glyoxylate $/ \mathrm{mg}$. dry-wt conidia $/ \mathrm{hr}$; the corresponding value for germinated conidia was $4.5 \mu \mathrm{g}$. glyoxylate $/ \mathrm{mg}$. dry-wt conidia $/ \mathrm{hr}$.

Table 1. Fatty acids obtained by the deacylation of the triglyceride
from Fusarium culmorum conidia
$\begin{gathered}\text { Carbon chain length } \\ \text { and degree of }\end{gathered}$
$\begin{array}{ccl}\text { unsaturation } & \% \text { of total } & \text { Probable identity } \\ 14: 0 & 0 \cdot 3 & \text { Myristic acid } \\ 16: 0 & 24 \cdot 0 & \text { Palmitic acid } \\ 16: 1 & 0 \cdot 5 & \text { Palmitoleic acid } \\ 18: 0 & 11 \cdot 0 & \text { Stearic acid } \\ 18: 1 & 31 \cdot 0 & \text { Oleic acid } \\ 18: 2 & 33 \cdot 2 & \text { Linoleic acid }\end{array}$

Table 2. Synthesis and utilization of storage lipid during germination of Fusarium culmorum conidia

\begin{tabular}{lccc}
\multicolumn{1}{c}{ Treatment } & $\begin{array}{c}\text { Total dry wt } \\
(\mathrm{mg} .)\end{array}$ & $\begin{array}{r}\text { Weight of } \\
\text { lipid (mg.) }\end{array}$ & $\begin{array}{c}\text { Lipid as \% of } \\
\text { total dry wt }\end{array}$ \\
Glucose+ ammonium sulphate & 88.4 & $31 \cdot 8$ & 36.0 \\
Glucose & $75 \cdot 3$ & 20.5 & $27 \cdot 2$ \\
Untreated control & 43.4 & $21 \cdot 3$ & 49.2
\end{tabular}

The difference, although small, appears to be a real one and therefore it would seem that lipid utilization did increase during germination. It is also probable that glyceride synthesis was increased by the presence of a nitrogen source.

The results of the isocitrate lyase assay were confirmed by the results of the ${ }^{14} \mathrm{C}$ labelling experiment. Comparisons of the actual and theoretical oxygen uptake values revealed that there was some stimulation of basal respiration in the presence of a nitrogen source. The percentage change in oxygen uptake due to basal respiration was very small when the conidia were supplied with glucose only $(+4.5 \%)$ but in the presence of glucose + ammonium sulphate the oxygen uptake due to basal respiration increased by $62.5 \%$. This stimulation is of the same order as that shown by the enzyme assay, which substantiates that the small difference recorded is in fact a real one.

\section{The fate of $\left[{ }^{14} \mathrm{C}\right]$ glucose in germinating conidia}

The distribution of ${ }^{14} \mathrm{C}$ from glucose into the various fractions of the conidia is given in Table 3 . The two treatments, with and without a nitrogen source, showed differences primarily in the amount of $\mathrm{CO}_{2}$ produced and in the insoluble material left 
after the extractions. The smaller amount of $\mathrm{CO}_{2}$ evolved in the absence of a nitrogen source agreed with the manometric data given earlier (Marchant \& White, 1966); the incorporation into insoluble material probably accounted for this difference. It has been shown that more glucose is assimilated in the absence of a nitrogen source (Marchant \& White, 1966) and this assimilated carbon seems to appear in the final insoluble fraction.

The chromatograms of the water-extracts revealed a large range of weakly labelled amino acids. The autoradiograms also showed small amounts of label in the organic acids of the tricarboxylic acid cycle. There were, however, two large spots of radioactivity which were tentatively ascribed to glucose and glucosamine (Fink, Cline \& Fink, 1963). The smaller of the two spots was subsequently cut out and eluted, then hydrolysed with sulphuric acid to confirm its identity as glucosamine. The products of hydrolysis were neutralized, as described above, with barium hydroxide and then

Table 3. The effect of ammonium sulphate on the metabolism of ${ }^{14} C$ glucose by Fusarium culmorum conidia

The values given are mean values calculated from duplicate experiments.

$\begin{array}{lcc}\text { Fraction } & \begin{array}{c}\text { With } \\ \text { ammonium } \\ \text { sulphate } \\ \text { (counts/100 sec.) }\end{array} & \begin{array}{c}\text { Without } \\ \text { ammonium } \\ \text { sulphate } \\ \text { (counts/100 sec.) }\end{array} \\ { }^{14} \mathrm{CO}_{2} \text { evolved } & 1682 & 1419 \\ \text { Water extract } & 6365 & 6920 \\ \text { Ethanol extract } & 596 & 565 \\ \text { Residual material } & 5964 & 6920\end{array}$

chromatographed in ethyl acetate + acetic acid + water $(3+3+1$, by vol.) with standards of $\left[\mathrm{U}^{-14} \mathrm{C}\right]$ glucose and 'cold' glucosamine. The results indicated that the compound was indeed glucosamine. There were no detectable differences between the treatments with and without a nitrogen source.

The chromatograms of the hydrolysed residue showed most heavy labelling in glucose with small quantities in xylose and mannose, galactose and arabinose were only weakly labelled, if at all. The differences between the two treatments were again difficult to detect.

\section{Carbon-dioxide fixation}

The distribution of ${ }^{14} \mathrm{C}$ fixed from ${ }^{14} \mathrm{CO}_{2}$ is given in Table 4. The majority of the fixed ${ }^{14} \mathrm{CO}_{2}$ was in the insoluble fraction with only small quantities in the more soluble fractions. The amount in the water extract is almost certainly attributable to the soluble 'primary' products of fixation.

The effect of $\mathrm{CO}_{2}$ concentration on fixation was marked, up to $0 \cdot 1 \%$ (v/v) ${ }^{14} \mathrm{CO}_{2}$, showing an almost linear increase in the rate of fixation. Above that concentration increasing concentrations of $\mathrm{CO}_{2}$ produced a smaller increase in fixed ${ }^{14} \mathrm{CO}_{2}$. However, even at the maximum concentration of ${ }^{14} \mathrm{CO}_{2}$ used $(0.83 \%$, v/v) the system was not saturated and increasing concentrations still resulted in increased fixation. Paper chromatography of the water extracts of these conidia produce unusual labelling patterns. The majority of the amino acids were unlabelled, with low degrees of labelling in the organic acids. Glutamic acid was fairly heavily labelled, but the largest 
concentration of ${ }^{14} \mathrm{C}$ was in a compound tentatively identified as glutamine. The thinlayer chromatograms of the ether extracts showed a uniform pattern of labelling throughout the glycerides.

\section{The effect of the nitrogen source on conidial swelling}

Marchant \& White (1966) showed that the ammonium ion was a suitable source of nitrogen for conidial swelling. To gain some idea of the part played by nitrogen in the swelling, potassium nitrate was substituted for ammonium sulphate as sole nitrogen source. The results showed that although the rate of swelling was initially

Table 4. The distribution of incorporated ${ }^{14} \mathrm{C}$ from ${ }^{14} \mathrm{CO}_{2}$ fixed by conidia of Fusarium culmorum

The values given are mean values calculated from duplicate experiments

$\begin{array}{lc}\quad \text { Fraction } & \text { Counts } / 100 \text { sec. } \\ \text { Water extract } & 674 \\ \text { Ethanol extract } & 117 \\ \text { Residual material } & 1255\end{array}$

Table 5. The effect of acetate on the swelling of Fusarium culmorum conidia

Treatment

Initial sample

Glucose + ammonium sulphate, $4 \cdot 5 \mathrm{hr}$

Acetate+ammonium sulphate, $4 \cdot 75 \mathrm{hr}$
Mean maximum conidial
width $(\mu)$

$5 \cdot 51$

$6 \cdot 19$

$5 \cdot 07$
S.E.

$\pm 0 \cdot 12$

$\pm 0 \cdot 10$

$\pm 0 \cdot 10$

slower in nitrate the final degree of swelling after $5 \mathrm{hr}$ was indistinguishable from that in ammonium sulphate. Ammonium sulphate supplied without glucose produced no effect on the size of the conidia. The result with nitrate suggested that nitrogen was probably involved metabolically in the swelling process, and that the lag period might represent a period of adaptation to nitrate as sole nitrogen source.

The effect of the concentration of ammonium sulphate on the rate of swelling was examined. Ammonium sulphate was supplied at 10,100 and $1000 \mu \mathrm{moles} /$ flask. The results showed that there was little difference between the results with 100 and 1000 $\mu \mathrm{moles} /$ flask; $10 \mu \mathrm{moles} /$ flask produced a decreased rate of swelling, but even this represented a substantial degree of swelling. These results suggest that the requirement for a nitrogen source was fairly small. The ability of sporangiospores of Rhizopus arrhizus to swell without an added nitrogen source may reflect a different nitrogen status in these sporangiospores.

\section{The effect of acetate on the conidial swelling}

Acetate does not support germination of conidia of Fusarium culmorum as sole carbon source (Marchant \& White, 1966), although it stimulates oxygen uptake. It can be seen from Table 5 that acetate did not produce any swelling of conidia, even in the presence of ammonium sulphate. If acetate were being utilized through the tricarboxylic acid and glyoxylate cycles then the role of carbon metabolism in conidial swelling involves pathways between glucose and acetate. 


\section{The effect of temperature and carbon-dioxide concentration on conidial swelling}

Examination was made of the effect of temperature on conidial swelling, to test that metabolic reactions were involved. It was possible that the effect on the conidia of glucose and ammonium sulphate was a direct one which allowed osmotic uptake of water. If this were so, lowering the temperature would not completely prevent conidial swelling. However, at $3^{\circ}$ conidial swelling was completely inhibited (Table 6).

Increased $\mathrm{CO}_{2}$ concentration inhibits the germination of conidia of Fusarium culmorum and the complete removal of $\mathrm{CO}_{2}$ is also inhibitory (Marchant, unpublished). In view of the role of $\mathrm{CO}_{2}$ fixation in the metabolism of the conidia it was thought that this system might play a part in conidial swelling. The experiment showed that over the range $0-5 \%(\mathrm{v} / \mathrm{v}) \mathrm{CO}_{2}$ in air there was no effect on swelling. Although this does not preclude the possible involvement of $\mathrm{CO}_{2}$ fixation in conidial swelling, it does mean that utilization of the products must be indirect.

Table 6. The effect of temperature on the swelling of Fusarium culmorum conidia

\begin{tabular}{lcc}
\multicolumn{1}{c}{ Treatment } & $\begin{array}{c}\text { Mean maximum conidial } \\
\text { width }(\mu)\end{array}$ & S.E. \\
Initial sample & 5.49 & \pm 0.08 \\
Glucose + ammonium sulphate, $25^{\circ}$ for $4.5 \mathrm{hr}$ & 6.65 & \pm 0.12 \\
Glucose + ammonium sulphate, $3^{\circ}$ for $4.5 \mathrm{hr}$ & 5.40 & \pm 0.08
\end{tabular}

\section{Pre-treatment and transfer experiments}

Samples of conidia of Fusarium culmorum were shaken for $16 \mathrm{hr}$ in a solution containing only glucose and were then transferred to solutions containing glucose, or ammonium sulphate or glucose +ammonium sulphate. The results indicated that while this treatment did not affect the ability of the conidia to swell when they were placed in glucose + ammonium sulphate, neither did it permit any swelling in ammonium sulphate only. It has already been shown (Marchant \& White, 1966) that glucose under these conditions is assimilated, and therefore the products of this assimilation are not available to bring about swelling when ammonium sulphate is supplied.

A similar pretreatment of the conidia with ammonium sulphate only showed that partial swelling occurred on transfer to a solution containing glucose, although swelling was not so great as in glucose + ammonium sulphate. This pretreatment with a nitrogen source did not remove the stimulation of oxygen uptake by conidia with glucose as substrate, which was noted previously (Marchant \& White, 1966), neither did it allow any germination when the conidia were suspended in glucose medium. It seems therefore that the role of ammonium sulphate in swelling and its role in the stimulation of oxygen uptake and germination can be separated.

When conidia were shaken for $1 \mathrm{hr}$ in glucose + ammonium sulphate, subsequent transfer to glucose medium produced no retardation of swelling. When, however, the conidia were transferred to ammonium sulphate medium then the conidia returned to their original condition. This reversal of swelling can be achieved even after $3 \mathrm{hr}$ in glucose + ammonium sulphate. All the results point to a product of metabolism as being the trigger responsible for conidial swelling. If this is so, then these results can be explained in terms of a product which is broken down in the presence 
of ammonium sulphate but without glucose, but this product is relatively stable in the presence of glucose or in the absence of ammonium sulphate.

The effect of glucosamine on conidial swelling and oxygen uptake

The results presented indicate that the possible trigger for swelling is a product involved in both carbon and nitrogen metabolism. The inability of acetate to serve as the carbon source suggested that the part of carbon metabolism concerned was involved in the pathway from glucose to pyruvate. Similarly the requirement for a small quantity of ammonium sulphate indicated the involvement of a nitrogencontaining compound. The compound most likely to satisfy the requirements appears to be glucosamine, which is formed in the presence of glucose and which could not be formed rapidly in any quantity from acetate.

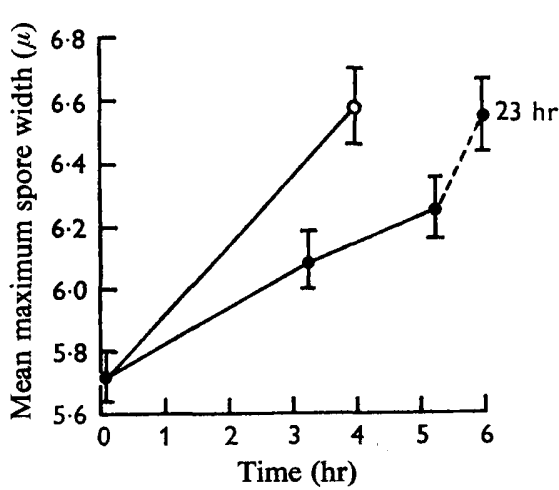

Fig. 1

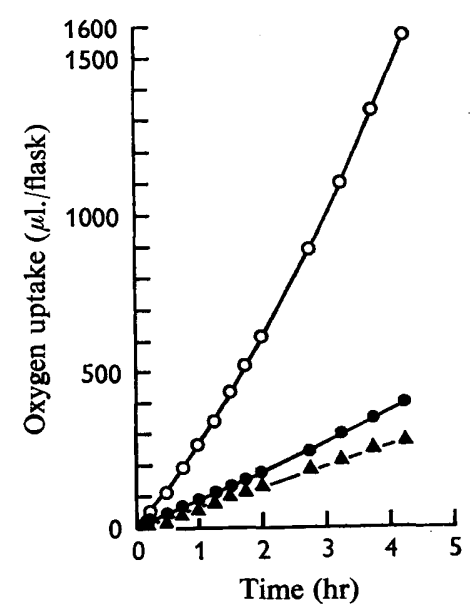

Fig. 2

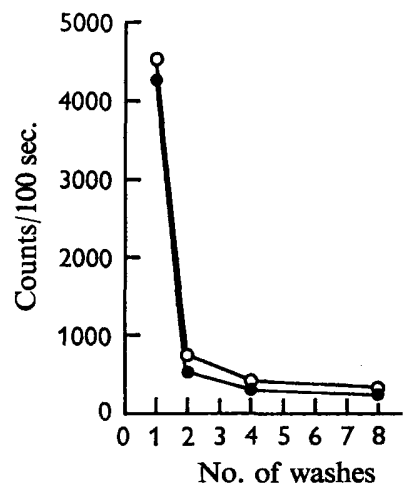

Fig. 3

Fig. 1. The effect of glucosamine on the swelling of the conidia of Fusarium culmorum. Standard errors are shown. $\mathrm{O}-\mathrm{O}$, Glucose+ammonium sulphate; - - , glucosamine. Fig. 2. Oxygen uptake by conidia of Fusarium culmorum supplied with: - - glucosamine; $\mathrm{O}-\mathrm{O}$, glucose + ammonium sulphate; $\boldsymbol{\Delta}-\mathbf{\Delta}$, buffer (pH 6.5).

Fig. 3. The loss of tritiated water from conidia of Fusarium culmorum treated with: $\bigcirc-O$, glucose + ammonium sulphate; -0, glucose.

To test this, conidia were shaken in glucosamine hydrochloride (500 $\mu$ moles/flask) and their swelling measured (Fig. 1); oxygen uptake was also observed as a measure of how much glucosamine was being respired (Fig. 2). Although the swelling in glucosamine was slower than in glucose + ammonium sulphate the final degree of swelling was quite high; stimulation of oxygen uptake by glucosamine was negligible and there was no evidence of any germination of conidia. The rate of swelling was more than ten times faster than would have been predicted from the oxygen uptake data if glucosamine were being converted to glucose + ammonia. The absence of any germination also argues against utilization of glucosamine in this way. 


\section{Permeability of the conidia}

The mode of action of the trigger compound was more difficult to test, but the loss of tritiated water from conidia was taken as a measure of their permeability, in one direction at least. The removal of tritiated water by successive washes with water from conidia shaken in glucose and in glucose + ammonium sulphate was measured (Fig. 3). The conidia swollen in glucose + ammonium sulphate had a higher initial radioactivity count, but the rate of loss of tritiated water was proportional to the initial value, indicating that there was no differential permeability.

\section{DISCUSSION}

To be able to discuss fully the implications of the physiological and fine structure studies of the conidia of Fusarium culmorum it is necessary to have some knowledge of their metabolism. Studies on the basal respiration (Marchant \& White, 1966) and fine structure (Marchant, 1966a) of conidia of $F$. culmorum showed that there was a basal respiratory substrate, which was probably a fat. It has long been known (Foster, 1949) that Fusarium species are capable of fat production on a large scale and this material has been taken to be a reserve carbon source. Characterization of this lipid has now shown that it is composed of triglycerides, with smaller quantities of the mono- and di-glycerides; these may represent intermediate stages in the synthesis and degradation of the triglycerides. Examination of the quantities of lipid in conidia during germination showed that there was a net synthesis of lipid, although the proportion of lipid of the total dry weight declined. There was also evidence that during germination there was an increase in the rate of utilization of this lipid, but this only occurred in the presence of a nitrogen source.

The distribution of ${ }^{14} \mathrm{C}$ from glucose into the various fractions of the conidia in the presence and absence of ammonium sulphate as nitrogen source did not seem to affect the metabolism in a qualitative manner; the labelling patterns were essentially similar. The presence of large quantities of glucosamine in the water-soluble fraction of the conidia, and the fact that there was no measurable incorporation into chitin in the walls, is of interest in connexion with work on the walls of Fusarium culmorum. Marchant (1966b) postulated that the germ-tube wall initially contains no chitin, but that this is deposited at a later stage, some distance behind the growing point. The evidence that other sugars are deposited in wall material supports this hypothesis of the growth of the germ tube. Also of relevance to the cell wall hypothesis is the evidence that one of the main products of $\mathrm{CO}_{2}$ fixation is glutamine; this compound, together with fructose-6-phosphate, forms the basis of glucosamine synthesis (Dixon $\&$ Webb, 1964). Carbon dioxide has an inhibitory effect on the germination of conidia of $F$. culmorum (Marchant, unpublished), and the control of chitin synthesis may be one way in which this is achieved.

Ekundayo (1966) proposed a theory for spore swelling in Rhizopus arrhizus which stated that the limiting factor was the availability of reduced nicotinamide nucleotide as a hydrogen donor for protein disulphide reductase. This enzyme is responsible for reducing disulphide linkages in the wall protein to sulphydryl groups, thereby increasing the plasticity of the wall. The main objection to this theory for Fusarium culmorum appears to be that there is no swelling of the conidia when they are placed 
in a glucose medium lacking ammonium sulphate as a nitrogen source. Under these conditions glucose is respired and reduced nictotinamide nucleotides are unlikely to be a limiting factor.

The swelling and germination of the conidia of Fusarium culmorum have thus been separated and it appears that swelling involves only part of the metabolism of germination. The results with glucosamine strongly suggest that this compound may be important in the initiation of conidial swelling. The relative inefficiency of the glucosamine used may have been due to its inability to enter the cells rapidly or to the inability of the conidia to utilize it efficiently in that form. It seems fairly certain that the glucosamine was not re-utilized as glucose + ammonia but exerted an effect on the elasticity of the conidial walls without becoming incorporated. Frey-Wyssling (1957) suggested a method of measuring the tensile strength of cell walls, but the mathematical treatment depends on a spherical cell and could not be applied to $F$. culmorum conidia. The results with tritiated water agree with those of Ekundayo (1966), who found no change in the permeability of sporangiospores of Rhizopus arrhizus during germination.

The authors wish to thank the Science Research Council for a grant held by one of them (R.M.) during the completion of this work.

\section{REFERENCES}

Cochrane, J. C., Cochrane, V. W., Simon, F. G. \& Spaeth, J. (1963). Spore germination and carbon metabolism in Fusarium solani. I. Requirements for spore germination. Phytopathology 53, 1155.

Cochrane, V. W., Cochrane, J. C., Collins, C. B. \& Serafin, F. G. (1963). Spore germination and carbon metabolism in Fusarium solani. II. Endogenous respiration in relation to germination. Am. J. Bot. 50, 806.

Cochrane, V. W., Cochrane, J. C., Vogel, J. M. \& Coles, R. S. (1963). Spore germination and carbon metabolism in Fusarium solani. IV. Metabolism of ethanol and acetate. J. Bact. 86, 312.

Cochrane, V. W., Berry, S. J., Simon, F. G., Cochrane, J. C., Collins, C. B., LeVy, J. A. \& Holmes, P. K. (1963). Spore germination and carbon metabolism in Fusarium solani. III. Carbohydrate respiration in relation to germination. $P l$. Physiol. 38, 533.

Dixon, M. \& WeBB, E. C. (1964). Enzymes, 2nd ed. London: Longmans.

EKUNDAYO, J. A. (1966). Further studies on germination of sporangiospores of Rhizopus arrhizus. J. gen. Microbiol. 42, 283.

Ekundayo, J. A. \& CARLILE, M. J. (1964). The germination of sporangiospores of Rhizopus arrhizus; spore swelling and germ-tube emergence. J. gen. Microbiol. 35, 261.

Fink, K., Cline, R. E. \& Fink, R. M. (1963). Paper chromatography of several classes of compounds: correlated $R_{F}$ values in a variety of solvent systems. Analyt. Chem. 35, 389.

FosTER, J. W. (1949). Chemical Activities of Fungi. New York: Academic Press.

FReY-Wyssling, A. (1957). Macromolecules in Cell Structure. Cambridge, Massachusetts: Harvard University Press.

Gotrlieb, D. (1963). Carbohydrate catabolism by fungi, in Proc. Symp. Chem. Biochem. Fungi and Yeasts; Dublin, p. 603, London: Butterworths.

HATCH, M. D. \& TURNER, J. F. (1960). A protein disulphide reductase from pea seeds. Biochem. J. 76, 556.

KORNBERG, H. L. \& MADSEN, N.B. (1958). The metabolism of $\mathrm{C}_{2}$ compounds in micro-organisms. 3. Synthesis of malate from acetate via the glyoxylate cycle. Biochem. J. 68, 549.

LOPEZ, M. E. \& FERGUS, C. L. (1966). The carbon and nitrogen nutrition of Fusarium roseum. Mycologia 57, 897.

Malins, D. C. \& Mangold, H. K. (1960). Analysis of complex lipid mixtures by thin-layer chromatography and complementary methods. J. Am. Oil Chem. Soc. 37, 576.

MARChant, R. (1966a). Fine structure and spore germination in Fusarium culmorum. Ann. Bot. N.S. 30, 441.

MARChANT, R. (1966b). Wall structure and spore germination in Fusarium culmorum. Ann. Bot. N.S. 30, 821 . 
MARCHANT \& R., WHITE, M. F. (1966). Spore swelling and germination in Fusarium culmorum. J. gen. Microbiol. 42, 237.

Morgan, T. E., Hanahan, D. J. \& EkHolm, J. (1963). A rapid method for deacylation of phospholipids and neutral lipids. Fedn Proc. Fedn Am. Socs exp. Biol. 22, 414.

Moses, V. (1957). The metabolic significance of the citric acid cycle in the growth of the fungus Zygorrhynchus moelleri. J. gen. Microbiol. 16, 534.

Nickerson, W. J. \& FALCONE, G. (1959). Function of protein disulfide reductase in cellular division of yeasts. In Sulfur in Proteins, p. 409. New York: Academic Press.

Randerath, K. (1963). Thin-layer Chromatography. New York: Academic Press. 